\title{
Pass/Fail: A Student Perspective on the Monumental Change Coming to USMLE Step 1
}

\author{
Daniel Childers ${ }^{1}$ \\ ${ }^{1}$ Georgetown University School of Medicine \\ Keywords: pass/fail, step 1, usmle \\ https://doi.org/10.52504/001c.13245
}

Georgetown Medical Review

Vol. 4, Issue 1, 2020

\begin{abstract}
As the United States Medical Licensing Examination moves to a pass/fail Step 1 exam, current medical students wonder what this will entail for their future and the future of medical education. This article provides background information and attempts to highlight the hopes, worries, and perspectives of medical students likely to be affected first by this momentous change.
\end{abstract}

I remember exactly where I was when a friend at another medical school told me the news a few months ago: sitting among our entire medical school class in the second level of the Dahlgren Memorial Library on the Georgetown University Medical Center. In the course of just a few short minutes, nearly every student had promptly shifted their attention from renal population health to their phone or a neighbor's computer screen displaying the same headline. Quizzical glances were shot across the room in every direction, the class Slack channels blew up, and a general sense of befuddlement swept through the windowless room. The significance of the announcement was clear to all, but its potential implications were just beginning to be imagined.

On February 12, it was announced that the United States Medical Licensing Examination (USMLE) Step 1 exam would be moving away from its 3-digit numeric scoring system; instead, students taking the exam after the date of transition would receive only a pass/fail result. ${ }^{1}$ Step 1 is taken about halfway through medical school and performance on the exam has been one of the primary factors considered in placing students into US residency programs for years. This announcement came on the heels of a prior statement from the National Board of Medical Examiners (NBME) and the Federation of State Medical Boards (FSMB) - the co-sponsors of the USMLE- that they had begun to consider such a change in $2019 .^{2}$ According to the official announcement in February and subsequent follow-up statements, this transition was not to be implemented before January of 2022. If the pass/fail reporting begins at its earliest possible date, most current medical students who have yet to take the Step 1 exam would still be on track to receive the classic 3-digit numerical score after they have completed it.

The biggest reason for the change, according to the February 2020 announcement, was that changing the score reporting to pass/fail will deemphasize the influence a single exam would have over the course of students' professional opportunities and will thus enhance medical student 
well-being during the years of their preclinical education. Furthermore, it satisfies the very fair criticism that so great a significance in the residency application process should not be placed on a single numerical score from an exam that is not clinically oriented, especially when no research exists to correlate Step 1 numerical scores to actual physician performance later on. By eliminating the numerical score, residency programs will no longer have the option to use this preclinical score as a principal means to screen and stratify applicants.

Immediately following the announcement of the scoring change, representatives from both the American Medical Association (AMA) and the Association of American Medical Colleges (AAMC), with whom discussions had been held about a potential shift, released statements in support of the decision citing the above reasons. ${ }^{1}$ Furthermore, many faculty were likely glad that more students may be able to focus their efforts on their school's curriculum rather than spend their days skipping in-person lectures and predominantly learning from third-party Step 1 review resources, as is currently quite common during the preclinical years of medical school.

On the surface, this immense reform seems to make sense on those terms: that it will augment student well-being and get students to engage more fully with each school's unique curriculum. However, there is no reason to believe that the emphasis and scrutiny that is currently placed on the numerical Step 1 score by residency programs will not simply be shifted elsewhere on applications, negating a major goal of relieving pressure on preclinical students in the name of well-being. Because most medical schools now have a pass/fail preclinical curriculum to boot, the only grades that could be reliably used for applicant stratification by programs are clinical clerkship grades. However, these grades are subjective and vary in implementation from preceptor to preceptor, let alone among all medical schools. Faculty letters and research experience could gain importance during the application process, but could also provide new terrain and extra fuel for intense competition between classmates gunning for the same competitive specialty.

In the accompanying question-and-answer session posted to the USMLE website with the initial announcement, it was acknowledged that the Step 2 Clinical Knowledge (CK) exam (which will be retaining its numerical score) taken during the clinical portion of medical school could supplant the Step 1 score in attention from and weight assigned by residency programs during the application process. ${ }^{3}$ While Step $2 \mathrm{CK}$ could likely be a better objective measurement of a particular student's ability to perform as a physician because the exam is clinically oriented, students may suffer from the extra consideration that score receives in other ways. Because most students take Step 2 CK at some point around the end of their third year of medical school and/or their core clerkships, there is not an abundance of time, if any, to adjust one's residency application upon receiving a score. Those students who were hoping to match 
into competitive programs and/or specialties may not meet their desired score, leaving just a matter of weeks to adjust their goals, fall in love with a new specialty, set up away rotations, and cultivate new faculty relationships in their new chosen field. This possibility stands in stark contrast to the certainty of the typical year-plus that a numerical Step 1 score allows for students to prepare their residency application strategy around before applying to programs. Frankly, this could be the stuff of nightmares for habitual planners and cause a new source of tremendous stress for these students.

In addition to the stress caused by future applications, there may be opportunities for differential selection bias to occur; that is, shifting emphasis on a student's application from their Step 1 exam upstream into the earlier portion of their curriculum vitae. For instance, prestigious programs looking to stratify applicants on additional objective grounds could use the perceived competitiveness or average MCAT score of their medical schools as a proxy for past performance on standardized exams, knowledge of basic science, and potential for producing translational research. As a result, medical schools with more impressive names would be able to place even more students into competitive programs, and students who chose to attend other institutions for scholarships, in-state tuition, or other financial reasons would not have the same ability to compete on an even playing field in this arena. International medical graduates could be similarly disadvantaged beyond what is already the norm, and better-connected students could leverage their relationships to an even higher degree in a world without a numerical Step 1 score as the equalizer. If we are not careful, any emerging biases related to this change are likely to lead to inequities among those students already at a disadvantage.

For many first-year medical students like myself who have yet to take the exam but will be given a numeric score when we do, there are other vital concerns to consider. While the date the exam will make the switch to pass/fail will presumably be a hard cutoff, the residency applications of students receiving numeric and pass/fail Step 1 scores will overlap for a number of years. This will occur in large numbers for the first year that pass/fail scores are on residency applications because the point in their curriculum at which students sit for the Step 1 exam significantly varies among medical schools. If January 2022 holds for when the change in score reporting occurs, students who take the exam during the customary preclinical years will apply for 2023 residency slots having received numerical scores.

On the other hand, schools that have their students wait until later in the curriculum to sit for the exam-including some of the highest-ranked research institutions such as Harvard University and the University of Pennsylvania-will see their class of 2023 student apply to residency in the same cycle but with only a "pass" on their application in lieu of a score. ${ }^{4,5}$ Additionally, multiple-degree students (who typically take Step 1 with their matriculating class but apply to residency years later) at any medical school 
will be applying under similar mixed conditions for years after this first cycle with heterogeneous score reports. How will this be handled? Will residency programs only see pass/fail status with numerical scores screened out in years that the applications are mixed? If so, for how long? If not, is that really fair? So far, there has been no indication which policy will be adopted, but any decision appears to come with considerable downsides.

All of the concerns enumerated to this point existed before the global coronavirus disease 2019 pandemic struck, adding to the existing uncertainty surrounding the implications of this precarious decision. While the USMLE addresses issues related to the in-person administration of its exams and a lack of available testing dates due to social distancing policies, some calls to amend the pass/fail decision have been made. In fact, there have been conflicting calls for delaying or expediting implementation of the pass/fail scoring system in relation to the originally intended date of January 2022. A student petition currently circulating online that, in part, asks the USMLE to consider moving the date of implementation of the pass/fail measure to a much earlier date. ${ }^{6}$ That petition has now amassed more than 2500 electronic signatures of medical students as of mid-May of $2020{ }^{7}$

With the myriad other issues facing the world of medicine at the moment, it is understandable that the once big news in medical education has taken a backseat in the public discourse for the time being. But the worries of preclinical medical students have only been amplified as we try to navigate our schooling while substantial uncertainty predominates on multiple fronts of our future education and professional careers. All attempts to improve medical student well-being should be commended. However, it is unclear what effects this sweeping decision will have on the students currently in its nearest proximity. Much worse than suboptimal incentives is a lack of clear incentives altogether, which is now exactly the paradigm under which preclinical medical students like myself are currently operating. It could be a while before we know whether the days we continue to invest in tediously memorizing mnemonics inside basement apartments all in the hopes of raising our Step 1 scores by just a couple points is actually time well-spent. We may find ourselves looking back and thinking that we should have prioritized our curriculum while also paying greater attention to the most impactful medical development in decades as it played out in real time around us.

Perhaps the best thing the USMLE could do, given the circumstances, is to delay the earliest possible date of Step 1 pass/fail implementation by 1 year or more so that the number of current students affected by the change becomes minimal and prospective students have more time to adjust their actions according to their best interests. But honestly, any definitive statement that could shed more light on how our futures are going to be determined would do much to empower students with knowledge around which to plan. Without that, are we not just trading one form of anxiety for another? Until such a 
revelation occurs, we as preclinical students will just have to join the rest of the world in hedging for very different futures from the stale comfort of social isolation. 


\section{REFERENCES}

1. United States Medical Licensing Examination. Invitational conference on USMLE scoring: Change to pass/fail score reporting for Step 1. Published February. February 2020.

https://www.usmle.org/incus/\#decision. Accessed May 11, 2020.

2. United States Medical Licensing Examination. Summary Report and Preliminary Recommendations from the Invitational Conference on USMLE Scoring (InCUS). https://www.usmle.org/pdfs/incus/incus_summary_report.pdf. Published March 12, 2019. Accessed May 11, 2020.

3. United States Medical Licensing Examination. In: Invitational Conference on USMLE Scoring: Updates. https://www.usmle.org/incus/\#updates. Accessed May 11, 2020.

4. Harvard Medical School. Pathways. https://meded.hms.harvard.edu/pathways. Accessed June 1, 2020 .

5. Perelman School of Medicine, University of Pennsylvania. Curriculum: Modules 5 and 6. https://www.med.upenn.edu/admissions/modules-5-6.html. Accessed June 1, 2020.

6. Frellick M. Students upset by USMLE response to COVID-19 demand changes. Medscape. https://www.medscape.com/viewarticle/929899. Published May 4, 2020. Accessed June 11, 2020.

7. Open letter to the NBME regarding Step exam administration during the COVID-19 pandemic. Published May. https://docs.google.com/forms/d/e/1FAIpQLSfGKnUgThczz6ws7WzlijrnTkj8rKhqJnjWJ42tya6TmBtcg/viewform. Published May 1, 2020. Accessed May $11,2020$. 